EXPERIMENTAL STUDY

\title{
Renal effects of recombinant prolactin in anaesthetized rats
}

\author{
S E Morrissey, T Newth, R Rees, A Barr, F Shora and J F Laycock \\ Department of Neuroendocrinology, Division of Neuroscience and Psychological Medicine, Imperial College School of Medicine, Charing Cross Hospital, \\ Fulham Palace Road, London W6 8RF, UK
}

(Correspondence should be addressed to J F Laycock; Email: j.laycock@ic.ac.uk)

\begin{abstract}
Objective: To re-examine the controversial possibility that prolactin exerts renal effects, using recombinant mouse prolactin $(\mathrm{rmP})$, in the presence and absence of circulating vasopressin.

Design: In experiment 1, the renal effects of $\mathrm{rmP}$ were examined in anaesthetized Brattleboro rats with hereditary hypothalamic diabetes insipidus (BDI) lacking circulating vasopressin and normal animals of the parent Long Evans (LE) strain. In experiment 2, salt and water excretion were studied in fluidloaded normal Sprague-Dawley (SD) rats, some of which received rmP.

Methods: In experiment 1, BDI and LE rats maintained in fluid balance were infused i.v. with each of three concentrations of $\mathrm{rmP}(10,20$ and $40 \mu \mathrm{g} / \mathrm{ml}$ per h) or maintained on $150 \mathrm{mmol} / \mathrm{l} \mathrm{NaCl}$ vehicle (controls). In experiment 2, the SD rats were infused with $75 \mathrm{mmol} / \mathrm{l} \mathrm{NaCl}$ in order to induce a state of diuresis comparable to that of BDI rats, some of them then receiving the $\mathrm{rmP}$ i.v.

Results: A profound $\mathrm{rmP}$-induced dose-dependent decrease in urine excretion $(P<0.005)$ and a lesser decrease in sodium excretion in the BDI rats was in marked contrast with the small but significant increase in urine excretion in the LE rats compared with controls $(P<0.025)$. The rmPinfused fluid-loaded SD rats also demonstrated a significant $(P<0.05)$ dose-related antidiuresis compared with the control animals, in addition to a decrease in sodium excretion.

Conclusions: These results show that prolactin has a profound antidiuretic effect in the absence of circulating vasopressin. In contrast, when vasopressin is present in the circulation rmP has a small, but opposite, diuretic effect. Thus the use of a recombinant prolactin has provided evidence for renal effects of this hormone which are modified in the presence of the circulating neurohypophysial hormone vasopressin.
\end{abstract}

European Journal of Endocrinology 145 65-71

\section{Introduction}

The adenohypophysial hormone prolactin is present in reptiles, birds, fish, amphibia and mammals and various actions have been identified. For example, this hormone has a crucial role in regulating salt and water balance in fish which migrate from salt to fresh water in order to breed (1), whereas in mammals the only clearly defined action of this hormone is its stimulation of milk production in post-partum females. However, other roles currently being investigated are likely to be of physiological importance, including immunological (e.g. 2, 3) and reproductive (e.g. 4, 5) actions. In the 1970 s and early 1980s, interest in possible renal actions of prolactin in mammals was aroused after various studies in humans and Brattleboro rats lacking the circulating antidiuretic hormone vasopressin. While some studies reported a prolactin-induced antidiuresis (6-10), others suggested that the effect was produced by contamination of the pituitary extract with vasopressin (11-14). A more recent study using a highly purified pituitary extract of prolactin has also clearly shown an antidiuretic effect, but only in Brattleboro rats with hereditary hypothalamic diabetes insipidus (BDI) lacking vasopressin (15). However, these BDI rats are believed to be exquisitely sensitive to vasopressin (16), so the possibility that the observed antidiuresis is produced by trace quantities of this hormone, present as an impurity in the pituitary extract, still cannot be excluded. The possibility that prolactin might stimulate the release of vasopressin has also been suggested (17), but this is unlikely, because the renal effects have been observed in BDI rats which are unable to produce the active hormone.

In order to evaluate further the potential effects of prolactin on salt and water excretion, a recombinant mouse prolactin was administered to anaesthetized BDI rats lacking circulating vasopressin and to normal rats in which vasopressin release was suppressed by volume expansion. 


\section{Methods}

All animals were adult males aged between 55 and 75 days, bred in the Department of Comparative Biology at the Charing Cross campus. Before the experiment all animals were housed in controlled conditions $(12 \mathrm{~h}$ light, $12 \mathrm{~h}$ darkness; room temperature approximately $21.5^{\circ} \mathrm{C}$, humidity approximately $50 \%$ ).

\section{General procedures}

On the day of experiment, each animal was anaesthetized with thiopentone (Trapanal, $100 \mathrm{mg} / \mathrm{kg}$ i.p.) and placed on a thermal blanket the temperature of which was regulated automatically via a rectal probe set at $37.4{ }^{\circ} \mathrm{C}$. Catheters were placed in (a) the bladder for urine collection, (b) the femoral artery for continuous recording of the heart rate and blood pressure via a transducer connected to a chart recorder or to a PC computer using Spike 2 software (Cambridge Electronic Devices, Cambridge, UK) and (c) a femoral vein for infusion. Timed urine samples were collected throughout, and volumes were determined gravimetrically; $\mathrm{Na}^{+}$and $\mathrm{K}^{+}$concentrations were measured by flame photometry (Instrumentation Laboratory 543). Recombinant mouse prolactin (rmP) kindly provided by AF Parlow (National Hormone and Pituitary Program) was lyophilised in $0.01 \mathrm{~mol} / \mathrm{l}$ $\mathrm{NaHCO}_{3}$ solution $(100 \mu \mathrm{l} / \mathrm{mg})$ and made up to $1 \mathrm{mg} / \mathrm{ml}$ with $150 \mathrm{mmol} / \mathrm{l} \mathrm{NaCl}$ before being divided into $250 \mu \mathrm{l}$ aliquots which were then frozen until used (within 10 days).

\section{Experiment 1}

Brattleboro rats with hereditary diabetes insipidus (BDI, $n=12$ ) and rats of the parent Long Evans (LE, $n=12$ ) strain were anaesthetized and prepared for surgery as described above. All rats received an i.v. infusion of $150 \mathrm{mmol} / \mathrm{l} \mathrm{NaCl}$ at a rate of $0.5 \mathrm{ml} / \mathrm{h}$ per $100 \mathrm{~g}$ and, when appropriate (i.e. for BDI rats), $2 \%$ glucose at a rate determined from the urine excretion in order to maintain fluid balance. After a minimum equilibration period of $60 \mathrm{~min}$ followed by a control period of $30 \mathrm{~min}$, six rats of each strain received $\mathrm{rmP}$ in the $150 \mathrm{mmol} / \mathrm{l} \mathrm{NaCl}$ infusion in increasing concentrations of 10,20 and $40 \mu \mathrm{g} / \mathrm{ml}$. Each concentration was infused for a period of $90 \mathrm{~min}$, the final one being followed by a control infusion period of $30 \mathrm{~min}$. Blood samples (approximately $0.5 \mathrm{ml} \mathrm{each}$ ) were taken halfway through each of the two control periods for determinations of haematocrit and the plasmas were used for $\mathrm{Na}^{+}$and $\mathrm{K}^{+}$concentration estimation. The experimental procedure for the remaining six rats of each strain was identical, except that there was no rmP in the saline infusion. All BDI rats were maintained in fluid balance by varying the rate of the $2 \%$ glucose infusion according to the urine excretion rate.

\section{Experiment 2}

Sprague-Dawley (SD) rats $(n=14)$ were anaesthetized and prepared for surgery as described above. All rats were infused with $75 \mathrm{mM} \mathrm{NaCl}$ at a rate of $3 \mathrm{ml} / \mathrm{h}$ per $100 \mathrm{~g}$ (infusion 1) throughout the equilibration period for approximately $120 \mathrm{~min}$, by which time the urine was large in volume and dilute, similar to that produced by BDI rats lacking vasopressin. During the subsequent control period of $30 \mathrm{~min}$, all rats received an additional infusion of $75 \mathrm{mmol} / \mathrm{l} \mathrm{NaCl}$ at a rate of $0.5 \mathrm{ml} / \mathrm{h}$ per $100 \mathrm{~g}$ and this infusion (infusion 2) was maintained throughout the remainder of the experiment. Then seven rats received $\mathrm{rmP}$ in the second $75 \mathrm{mmol} / \mathrm{l} \mathrm{NaCl}$ infusion in increasing concentrations of 10,20 and $40 \mu \mathrm{g} / \mathrm{ml}$ each for a period of $90 \mathrm{~min}$, followed by a final control infusion period of $30 \mathrm{~min}$. Blood samples (approximately $0.5 \mathrm{ml}$ each) were taken half-way through each of the two control periods for haematocrit determinations, the plasmas being used for $\mathrm{Na}^{+}$and $\mathrm{K}^{+}$concentration estimation. The experimental procedure for the remaining seven rats was identical, except that there was no rmP in the saline infusion. Fluid balance for all animals was maintained throughout by varying the rate of infusion 1 according to the urine excretion rate.

\section{Statistics}

All data are presented as means \pm s.E.M. Group differences were compared using a one-way analysis of variance followed by i multiple comparison tests to determine differences between groups. When appropriate, Student's $t$-tests were used for comparisons between two groups. Differences between groups were taken to be statistically significant whenever $P<0.05$.

\section{Results}

\section{Experiment 1}

Urine production There was a gradual increase in urine flow rate initially, settling out at about $120 \mu \mathrm{l} / \mathrm{min}$ as indicated by the change in urine production observed in the control BDI rats (Fig. 1). Such a urine production, over $24 \mathrm{~h}$, would be comparable to the daily urine volume produced by a conscious BDI rat. The initial increase in urine flow rate was similar in the rmP-infused BDI rats, but the two greater infusions of 20 and $40 \mu \mathrm{g} / \mathrm{ml}$ were associated with significantly lower urine production than that in the controls (Fig. 1), indicative of an antidiuretic effect in these animals. There was a similar proportional increase in, and stabilization of, urine flow rate in the control LE rats, albeit at a much lower level (comparable over $24 \mathrm{~h}$ to the daily urine volume produced by a conscious LE rat). In the rmP-treated LE rats, in contrast, the greater doses were associated with 
an increase in urine production compared with the LE controls, indicative of a small diuretic effect (Fig. 1).

In an earlier study using BDI and LE rats (15), prolactin concentrations were measured before the infusion of pituitary prolactin extract at the same three doses following the same experimental procedure, and at the end of the experiment after the highest concentration used. The (previously unpublished) values for plasma prolactin before and after infusions with the hormone were $4.95 \pm 1.05$ and $199 \pm$ $9.5 \mathrm{ng} / \mathrm{ml}$ in the LE rats, and $3.2 \pm 0.5$ and $177 \pm$ $15 \mathrm{ng} / \mathrm{ml}$ in the BDI rats.

Sodium excretion Similar though less marked differences associated with $\mathrm{rmP}$ were seen with respect to sodium excretion. Thus, for BDI rats, the rmP was associated with a decrease in sodium excretion compared with the appropriate controls, whereas a small but insignificant natriuresis was observed in the LE rats compared with their controls (Fig. 2).

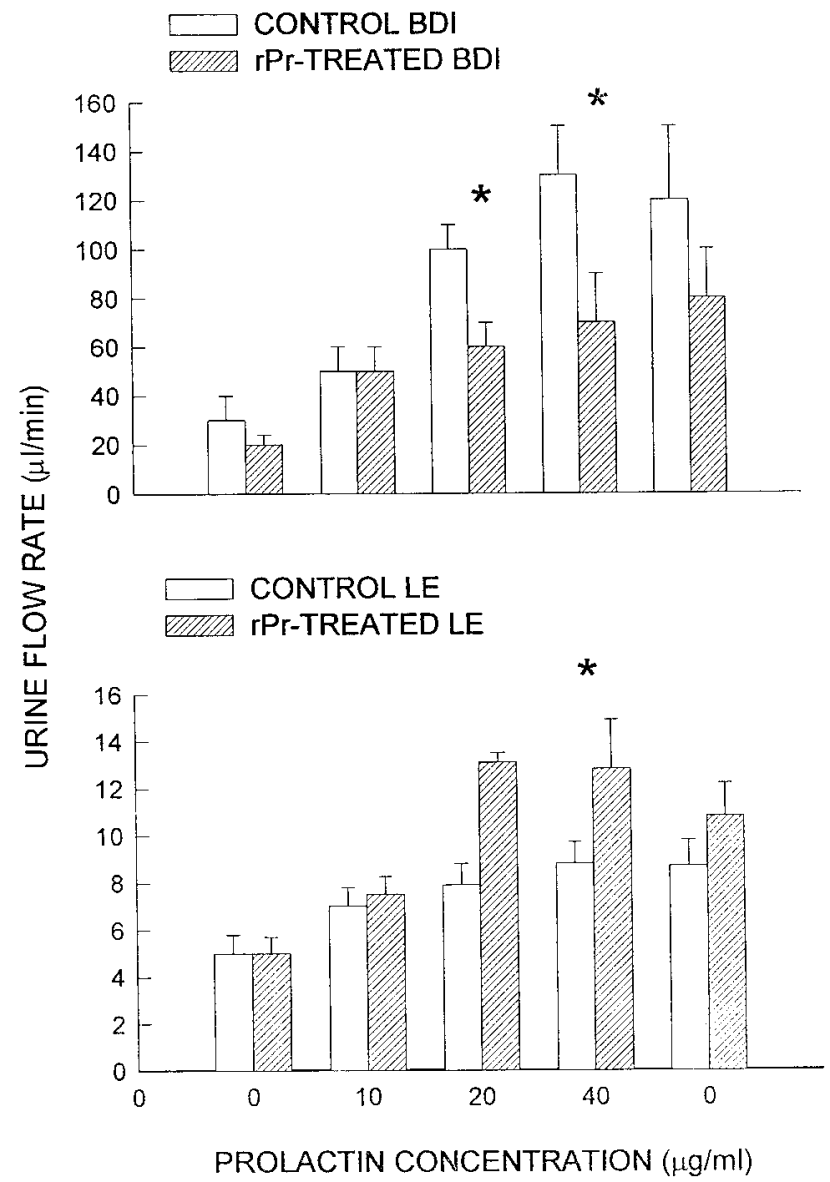

Figure 1 Effect of different concentrations of recombinant prolactin $(\mathrm{rPr})$ or vehicle (controls) on the urine flow rate (means \pm S.E.M.) of $\mathrm{BDI}$ rats (upper panel) and normal LE rats (lower panel). ${ }^{\star} P<0.05$ for significant differences between the treated and control groups.
Potassium excretion There were no marked effects of rmP on potassium excretion in BDI or LE rats, although the middle concentration of $\mathrm{rmP}$ was associated with a small but significant decrease and increase in potassium excretion in BDI and LE rats respectively (Fig. 3).

\section{Experiment 2}

Urine production A diuresis was first established in the SD rats such that the urine production rate (approximately $170 \mu \mathrm{l} / \mathrm{min}$ ) was comparable to that seen in BDI rats (Fig. 4). There was no further change in urine flow in the control SD rats, but in the rmPtreated animals there was a significant $(P<0.05)$ dose-dependent decrease, which continued into the final 30-min control period (Fig. 4). Multiple comparison analysis indicated that the difference between the groups reached statistical significance $(P<0.05)$ with the $40 \mu \mathrm{g} / \mathrm{ml} \mathrm{rmP}$ concentration.

Sodium excretion Sodium excretion was significantly $(P<0.05)$ lower in the rmP-treated rats than in the

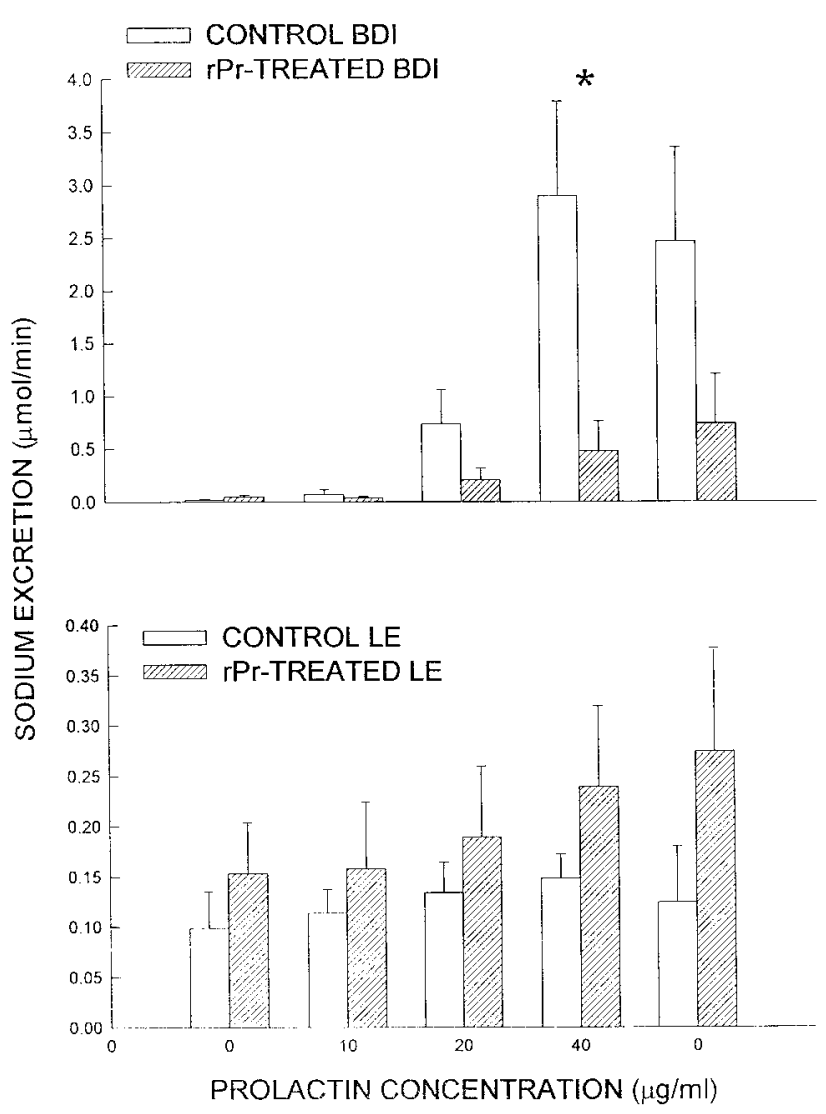

Figure 2 Effect of different concentrations of recombinant prolactin $(\mathrm{rPr})$ or vehicle (controls) on the urinary sodium excretion rate (means \pm S.E.M.) of BDI rats (upper panel) and normal LE rats (lower panel). ${ }^{*} P<0.05$ for significant differences between the treated and control groups. 


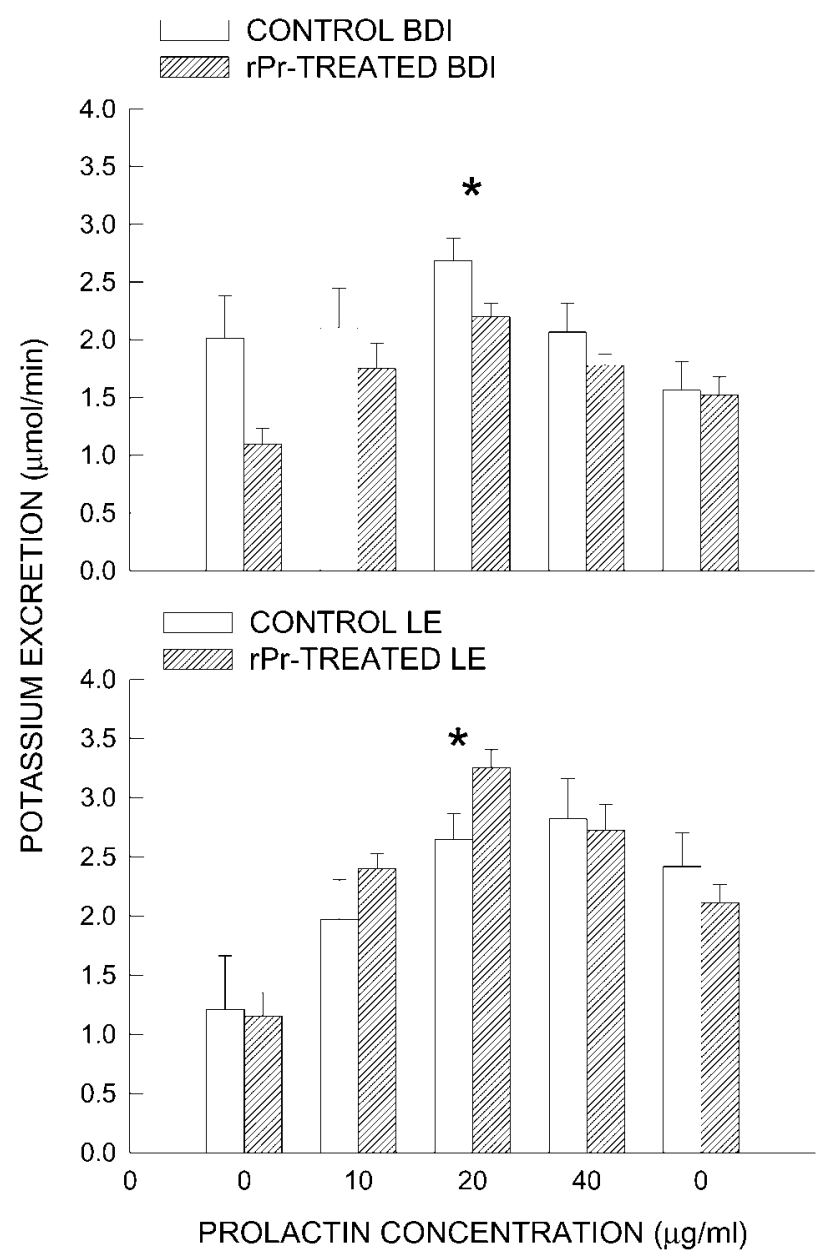

Figure 3 Effect of different concentrations of recombinant prolactin $(\mathrm{rPr})$ or vehicle (controls) on the urinary potassium excretion rate (means \pm S.E.M.) of BDI rats (upper panel) and normal LE rats (lower panel). ${ }^{\star} P<0.05$ for significant differences between the treated and control groups.

controls, although individual differences between the groups at any point could not be identified (Fig. 5).

Potassium excretion The potassium excretion decreased throughout the experiment in both groups of animals, but there was an overall small but significantly $(P<0.05)$ lower excretion in the rmPtreated rats. However, no significant differences at specific points could be identified between the groups (Fig. 6).

There were no significant differences between the rmP-treated and control rats with respect to either heart rate or arterial blood pressure at any stage. By the end of the experiment, the fluid balance status (overall fluid infused minus urine excreted) of both groups of animals was similar and slightly positive by approximately $3 \mathrm{ml} / \mathrm{rat}$, which would have balanced (to an unknown extent) the inevitable invisible water

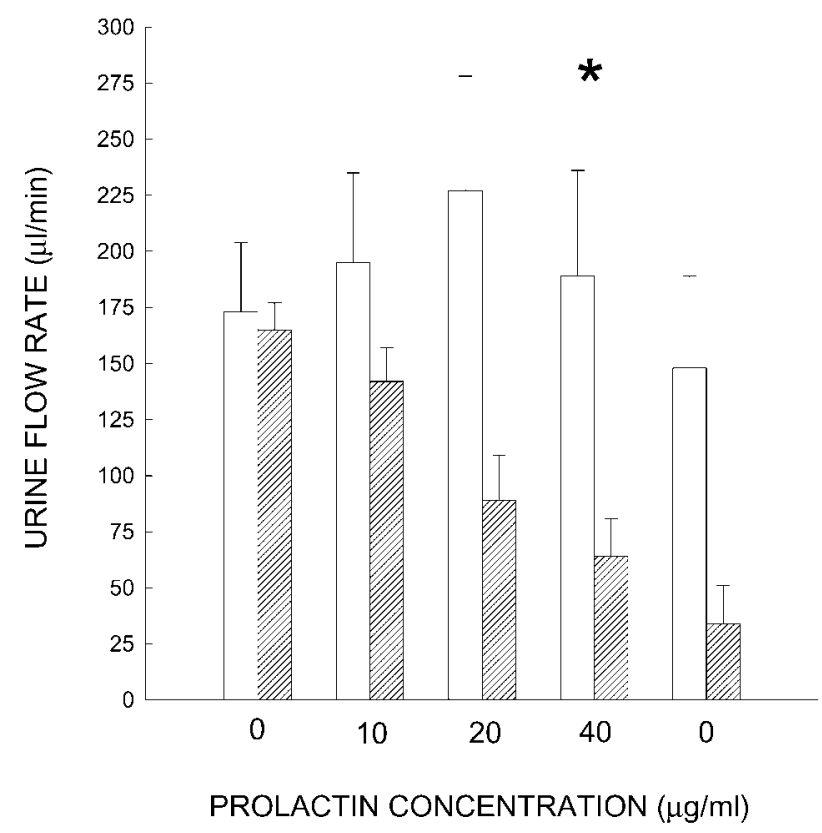

Figure 4 Effect of different concentrations of recombinant prolactin $(\mathrm{rPr})$ or vehicle (controls) on the urine flow (means \pm S.E.M.) rate of normal SD rats undergoing diuresis. ${ }^{*} P<0.05$ for significant differences between the treated and control groups.

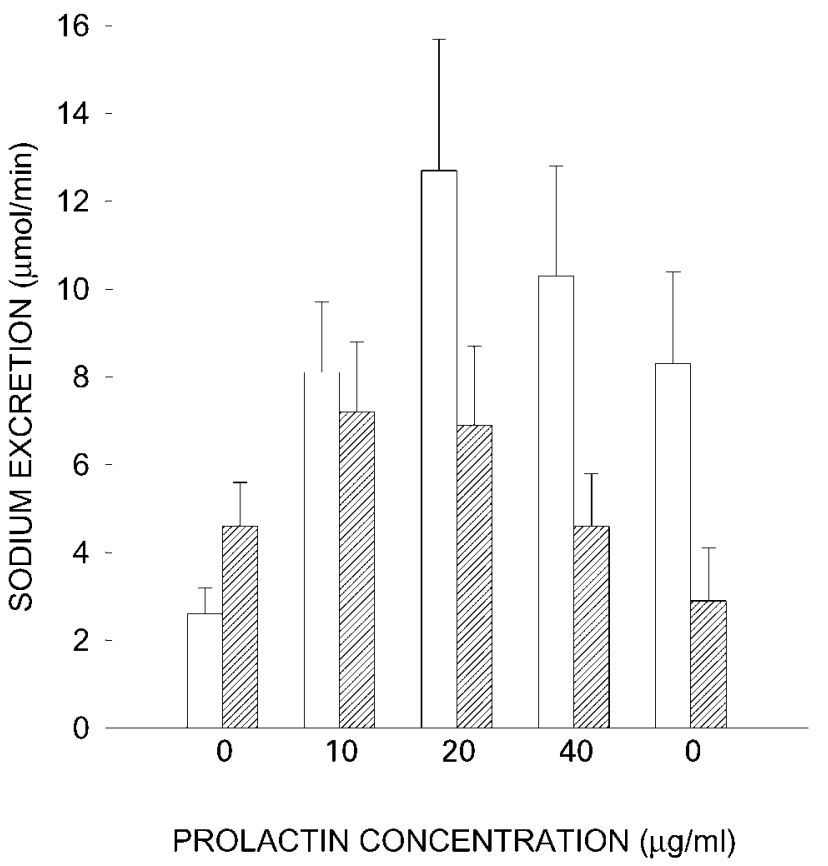

Figure 5 Effect of different concentrations of recombinant prolactin $(\mathrm{rPr})$ or vehicle (controls) on the urinary sodium excretion rate (means \pm S.E.M.) of normal SD rats undergoing diuresis. 


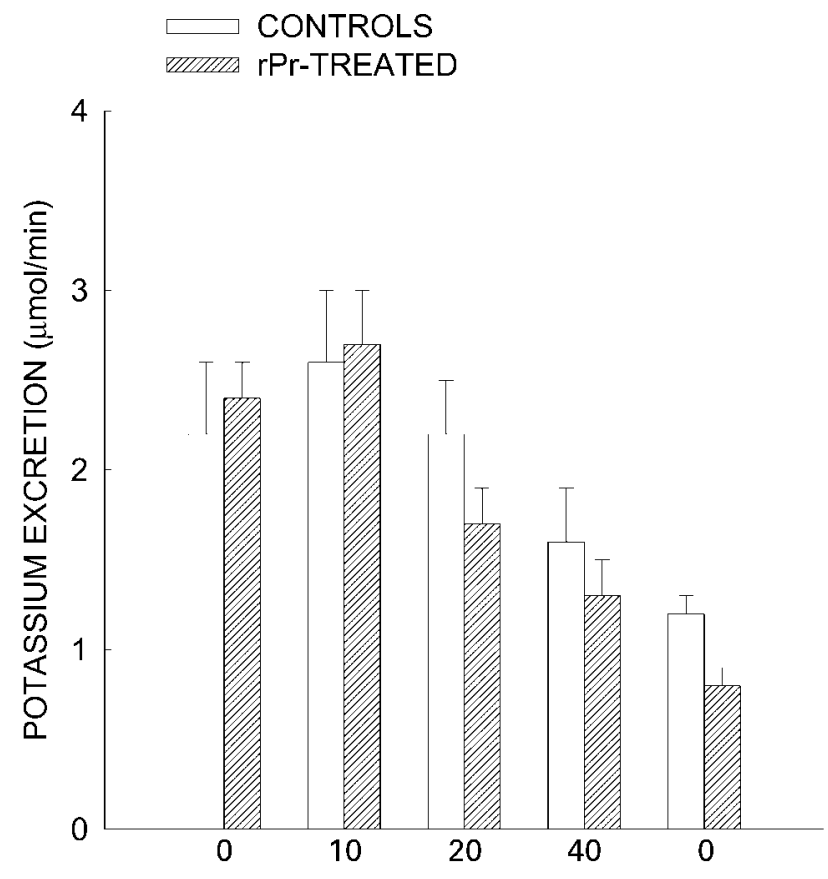

PROLACTIN CONCENTRATION $(\mu \mathrm{g} / \mathrm{ml})$

Figure 6 Effect of different concentrations of recombinant prolactin $(\mathrm{rPr})$ or vehicle (controls) on the urinary potassium excretion rate (means \pm S.E.M.) of normal SD rats undergoing diuresis.

loss through respiration. Further evidence that fluid balance was adequately maintained throughout the study was provided by the haematocrit values, which were similar at the beginning and end of each experiment in all animals. Furthermore, no significant changes in plasma sodium and potassium concentrations could be detected over the course of the experiment in either group of rats.

\section{Discussion}

The present studies have re-investigated the renal and cardiovascular effects of prolactin, in the absence of vasopressin contamination, by using a mouse recombinant prolactin $(\mathrm{rmP})$ preparation.

The first experiment, examining the renal and cardiovascular effects of $\mathrm{rmP}$ in Brattleboro rats with hereditary hypothalamic diabetes insipidus (BDI), provided evidence of sodium and water retention in the absence of circulating vasopressin. These effects were absent in the normal LE control animals; indeed, a small increase in urine flow was observed, in agreement with the findings of an earlier study (18). Cardiovascular effects were not apparent in either BDI or LE animals. Thus the effects of prolactin on renal salt and water retention appear to be present only when the normal antidiuretic hormone vasopressin is absent from the circulation, and are independent of significant increases in arterial blood pressure. Both pituitary and plasma prolactin concentrations in male BDI rats are normal when compared with weight-matched LE rats (19), although another report claims that circulating concentrations are lower than in controls but restored after treatment with a $V_{2}$ receptor agonist (20). The latter finding would be in accordance with the suggestion that vasopressin has a stimulatory effect on prolactin release (21). Either way, it is extremely unlikely that endogenous prolactin will influence the present findings after the administration of exogenous hormone to the BDI rats, particularly because there is evidence for negative (short-loop) feedback by this hormone on its own release (22). However, either as a direct consequence of the absence of other effects of vasopressin, or indirectly as compensatory mechanisms may be present, the BDI rat may not be the ideal model for such investigations.

The second experiment was designed to determine whether the observed effects were somehow pertinent only to Brattleboro rats, in which various other compensatory differences generally associated with the absence of vasopressin, such as an enhanced renin-angiotensin activity (23) and possible central effects (24), are present. Therefore, normal SD rats, in which the neurohypophysial vasopressin system was inhibited by an increased fluid load, were used. Again, the rats infused with rmP showed a clear, dosedependent, antidiuresis (and sodium retention) compared with the similarly fluid-loaded, but vehicle infused, controls. Thus the present study provides evidence of renal effects for prolactin in both normal rats and Brattleboro rats, suggesting that these effects are detectable only when the vasopressin system is absent or inhibited. This could explain the absence of any obvious renal abnormalities in prolactin receptor knockout mice, in which the neurohypophysial system is assumed to be functioning normally (25). It is interesting to note that in normal rats (e.g. the LE rats in experiment 1) rmP induced a small diuresis, which was converted into an antidiuresis in the absence (or suppression) of circulating vasopressin. These findings are reminiscent of the paradoxical, and still not completely understood, antidiuretic effect of thiazide diuretics in diabetes insipidus $(26,27)$.

As indicated earlier (see Results) plasma prolactin concentrations were measured before and after the infusion of the same three doses of prolactin from purified pituitary extract, in a previous preliminary study in our laboratory. The levels reached, in both BDI and LE rats, were similar and were within the normal physiological range - at least for female rats suggesting that the renal effect could well be relevant to water retention in pregnancy, for instance.

At present, the mechanism (or mechanisms) by which prolactin influences renal function, particularly in relation to the presence/absence of vasopressin, is unclear. Three general mechanisms can be considered: 
(a) direct effects on the renal nephron, (b) indirect effects via alterations in renal haemodynamics and (c) indirect effects through prolactin-mediated actions on non-renal target tissues.

Firstly, considering the possibility of a direct action on the renal nephron, binding studies have localised prolactin receptors to the proximal tubule (28) and to the thick ascending limb of the loop of Henlé, the distal convoluted tubule and the collecting duct (29). A micropuncture study has also implicated the distal nephron as possible site of action of prolactin (30), but there is a dearth of physiological studies examining this issue.

Secondly, prolactin could indirectly influence renal function by altering the haemodynamics of the kidney, such as renal plasma flow and glomerular filtration rate. Renal haemodynamic effects and changes in glomerular filtration rate have not been invariably associated with acute prolactin administration (31); however, they could be relevant in chronic hyperprolactinaemia (32). Certainly, renal haemodynamics and fluid handling are both altered during pregnancy, when circulating prolactin (and the related hormone placental lactogen) concentrations are increased. It is also fascinating to appreciate that circulating concentrations of inactivating enzymes for the neurohypophysial hormones are increased during pregnancy (33).

The third possibility, that prolactin could have an indirect renal effect via some action on a non-renal tissue, is exemplified by the finding that prolactin receptors are present on the glomerulosa cells of the adrenal cortex (34). Furthermore, prolactin administration has been associated with an increased aldosterone secretion by rat zona glomerulosa cells (35). These findings are suggestive of a possible influence on aldosterone release with a consequent salt-retaining effect, possibly resulting in a vasopressin-independent increase in water reabsorption.

The possibility that there might be a direct renal interaction between prolactin and vasopressin at the cellular level is also intriguing. Prolactin binds to two membrane receptors forming a homodimer, with the subsequent stimulation of a cytoplasmic tyrosine kinase (JAK 2) as the initial component of the activated intracellular pathway (25). In contrast, it is generally accepted that vasopressin stimulates adenylyl cyclase after initial binding to its $V_{2}$ receptor in the cell membrane. It is interesting to note that both prolactin and vasopressin have been shown to stimulate the same enzyme, $\mathrm{Na}^{+}-\mathrm{K}^{+}$-ATPase, in the thick ascending limb of the loop of Henle $(29,36)$ and that prolactin may actually stimulate adenylyl cyclase in the collecting duct (29). Thus the activation of an intracellular adenylyl cyclase-induced pathway by prolactin, perhaps when the dominant hormonal influence (vasopressin) on that pathway is removed, is an intriguing possibility.
In conclusion, the present study provides evidence for a specific effect of prolactin on renal salt and water reabsorption in the absence of normal circulating concentrations of vasopressin. Further studies are required to investigate the precise site and mechanism of action of these particular effects of prolactin.

\section{Acknowledgements}

We are very grateful to Dr A-F Parlow (National Hormone and Pituitary Program, USA) for the donation of mouse recombinant prolactin.

\section{References}

1 Nicoll CS. Physiological actions of prolactin. In Handbook of Physiology, Section 7: Endocrinology, pp 253-292. Eds E Knobil \& WH Sawyer. Washington DC: American Physiological Society, 1974.

2 Bernton EW, Meltzer MS \& Holaday MW. Suppression of macrophage activation and T-lymphocyte function in hyperprolactinemic mice. Science $1988 \mathbf{2 3 9} 401-404$.

3 Yu-Lee L-Y. Molecular actions of prolactin in the immune system. Proceedings of the Society for Experimental Biology and Medicine 1997215 35-51.

4 Armstrong DT, Knudsen KA \& Miller LS. Effect of prolactin on cholesterol metabolism and progesterone biosynthesis in corpora lutea of rats hypophysectomized during pseudopregnancy. Endocrinology 197086 634-641.

5 Albarracin CT \& Gibori G. Prolactin action on luteal protein expression in the corpus luteum. Endocrinology $1991 \mathbf{1 2 9}$ $1821-1830$.

6 Miller M, van Gemert M \& Moses AM. Prolactin-induced antidiuresis in the rat with diabetes insipidus. Federation Proceedings $197433 \mathrm{P} 285$.

7 Miller M \& van Gemert M. Antidiuretic action of prolactin in the rat with diabetes insipidus. Hormone Research 19767 319-322.

8 Buckman MT, Peake GT \& Robertson G. Hyperprolactinaemia influences renal function in man. Metabolism 197625 509516.

9 Mtabaji JP, Manku MS \& Horrobin DF. Effect of prolactin, antidiuretic hormone and aldosterone in the syndrome produced by lithium treatment in male rats. Journal of Endocrinology 1975 $6757 P$.

10 Horrobin DF. Prolactin as a regulator of fluid and electrolyte metabolism in mammals. Federation Proceedings 1980392567 2570.

11 Carey RM, Johanson AJ \& Seif SM. The effects of ovine prolactin on water and electrolyte excretion in man are attributable to vasopressin contamination. Journal of Clinical Endocrinology and Metabolism $1977 \mathbf{4 4} 850-858$.

12 Vorherr H, Vorherr UF \& Solomon S. Contamination of prolactin preparations by antidiuretic hormone and oxytocin. American Journal of Physiology 1978234 F318-F324.

13 Adler RA, Dolphin S, Szefler M \& Sokol HW. Effects of elevated circulating prolactin in rats with hereditary hypothalamic diabetes insipidus (Brattleboro strain). Endocrinology 1979106 1001-1006.

14 North WG, Gellai M, Sokol HW \& Adler RA. Demonstration that rat prolactin has no intrinsic antidiuretic activity in the rat. Hormone Research 198115 55-64.

15 Abusnana SEE, Morrissey SE, Cowell A-M \& Laycock JF. Purified prolactin influences cardiovascular and renal function in Brattleboro rats with hereditary diabetes insipidus. Journal of Endocrinology 1997152 (Suppl) P181.

16 Jones JJ \& Lee J. The value of rats with hereditary hypothalamic diabetes insipidus for the bioassay of vasopressin. Journal of Endocrinology 196737 335-344. 
17 Laczi F, Szasz A, Vecsernyes M \& Julesz J. Neurohypophysial hormone secretion in hyperprolactinaemic women. Neuropeptides 199832 435-437.

18 Adler RA, Herzberg VL, Brinck-Johnsen T \& Sokol W. Increased water excretion in hyperprolactinaemic rats. Endocrinology 1986 118 1519-1524.

19 Adler RA \& Sokol HW. Prolactin and growth hormone in the unstressed Brattleboro rat. Annals of the New York Academy of Sciences $1982394607-613$.

20 Fujimoto $\mathrm{S} \&$ Hedge GA. Alterations in pituitary function in rats with hypothalamic diabetes insipidus (Brattleboro strain). Annals of the New York Academy of Sciences $1982394614-$ 618.

21 Kjaer A. Vasopressin as a neuroendocrine regulator of anterior pituitary hormone secretion. Acta Endocrinologica 1993129 489-496.

22 Wardlaw SL, Kim J \& Matera C. Effect of chronic prolactin infusion on pituitary prolactin and hypothalamic proopiomelanocortin. Journal of Neuroendocrinology $1997981-85$.

23 Mohring B, Mohring J, Dauda G \& Haack D. Potassium deficiency in rats with hereditary diabetes insipidus. American Journal of Physiology 1974227 916-920.

24 Laycock JF, Chatterji U, Seckl JR \& Gartside IB. The abnormal quinine drinking aversion in the Brattleboro rat with diabetes insipidus is reversed by the vasopressin agonist DDAVP: a possible role for vasopressin in the motivation to drink. Physiology and Behavior 199455 407-412.

25 Bole-Feysot C, Goffin V, Edery M, Binart N \& Kelly PA. Prolactin (PRL) and its receptor: actions, signal transduction pathways and phenotypes observed in PRL receptor knockout mice. Endocrine Reviews $199819225-268$.

26 Walter SJ, Skinner J, Laycock JF \& Shirley DG. The antidiuretic effect of chronic hydrochlorothiazide treatment in rats with diabetes insipidus: water and electrolyte balance. Clinical Science $198263525-532$.

27 Shirley DG, Walter SJ \& Laycock JF. The antidiuretic effect of chronic hydrochlorothiazide treatment in rats with diabetes insipidus: renal mechanisms. Clinical Science $198263533-$ 538 .

28 Mountjoy K, Cowden EA, Dobbie JW \& Ratcliffe JG. Prolactin receptors in the rat kidney. Journal of Endocrinology $1980 \mathbf{8 7}$ $47-54$.

29 Evan AP, Palmer GC, Lucci MS \& Solomon S. Prolactin-induced stimulation of rat adenylate cyclase and autoradiographic localization to the distal nephron. Nephron 197718 266-276.

30 Stier CT, Cowden EA, Friesen HG \& Allison MEM. Prolactin and the rat kidney: a clearance and micropuncture study. Endocrinology $1984115362-367$.

31 Riley AL, Hagen TC \& Stefaniak JE. Effect of prolactin on glomerular filtration rate. Clinical Science 197855 335-339.

32 Garland HO, Lewis AG \& Milne CM. Altered renal function in chronically hyperprolactinaemic rats. Journal of Physiology 1987 $39413-21$.

33 Pliska V, Barth T \& Rychlik I. Effect of human serum oxytocinase on the antidiuretic action of lysine vasopressin and oxytocin in the rat. Experientia 196723 196-197.

34 Glasow A, Briedert M, Haidan A, Anderegg U, Kelly PA \& Bornstein SR. Functional aspects of the effect of prolactin (PRL) on adrenal steroidogenesis and distribution of the PRL receptor in the human adrenal gland. Journal of Clinical Endocrinology and Metabolism $1996 \mathbf{8 1} 3103-3111$.

$35 \mathrm{Kau}$ M-M, Lo M-J, Tsai S-C, Chen J-J, Pu H-F, Chien EJ et al. Effects of prolactin on aldosterone secretion in rat zona glomerulosa cells. Journal of Cellular Biochemistry 199972 286-293.

36 Imbert-Teboul M, Charbardes D, Montegut M, Vlique A \& Morel F. Vasopressin-dependent adenyl cyclase activities in the rat kidney medulla: evidence for two sites of action. Endocrinology 1978 $1021254-1261$.

Received 8 November 2000

Accepted 28 March 2001 